\title{
The Use of Mucoadhesive Polymers to Enhance the Hypotensive Effect of a Melatonin Analogue, 5-MCA-NAT, in Rabbit Eyes
}

\author{
Vanessa Andrés-Guerrero, ${ }^{1}$ Irene T. Molina-Martínez, ${ }^{1}$ Assumpta Peral, ${ }^{2}$ \\ Beatriz de las Heras, ${ }^{3}$ Jesús Pintor, ${ }^{4}$ and Rocío Herrero-Vanrell ${ }^{1}$
}

Purpose. 5-Methoxy-carbonylamino- $N$-acetyltryptamine (5MCA-NAT, a melatonin receptor agonist) produces a clear intraocular pressure (IOP) reduction in New Zealand White rabbits and glaucomatous monkeys. The goal of this study was to evaluate whether the hypotensive effect of 5-MCANAT was enhanced by the presence of cellulose derivatives, some of them with bioadhesive properties, as well as to determine whether these formulations were well tolerated by the ocular surface.

MetнoDs. Formulations were prepared with propylene glycol $(0.275 \%)$, carboxymethyl cellulose (CMC, $0.5 \%$ and $1.0 \%)$ of low and medium viscosity and hydroxypropylmethyl cellulose $(0.3 \%)$. Quantification of 5-MCA-NAT $(100 \mu \mathrm{M})$ was assessed by HPLC. In vitro tolerance was evaluated by the MTT method in human corneal-limbal epithelial cells and normal human conjunctival cells. In vivo tolerance was analyzed by biomicroscopy and specular microscopy in rabbit eyes. The ocular hypotensive effect was evaluated measuring IOP for 8 hours in rabbit eyes

RESULTS. All the formulations demonstrated good in vitro and in vivo tolerance. 5-MCA-NAT in CMC medium viscosity $0.5 \%$ was the most effective at reducing IOP (maximum IOP reduction, $30.27 \%$ ), and its effect lasted approximately 7 hours.

Conclusions. The hypotensive effect of 5-MCA-NAT was increased by using bioadhesive polymers in formulations that are suitable for the ocular surface and also protective of the eye in long-term therapies. The use of 5-MCA-NAT combined with bioadhesive polymers is a good strategy in the treatment of ocular hypertension and glaucoma. (Invest Ophthalmol Vis Sci. 2011;52:1507-1515) DOI:10.1167/iovs.10-6099

From the Departments of ${ }^{1}$ Pharmacy and Pharmaceutical Technology and ${ }^{3}$ Pharmacology, School of Pharmacy, and the Departments of ${ }^{2}$ Optics II (Optometry and Vision) and ${ }^{4}$ Biochemistry and Molecular Biology IV, School of Optics, Complutense University, Madrid, Spain.

Supported by the Spanish Ministry of Health (RETICSnet ED07/ 0062/2002 and RETICS RD07/006/0004), Ministerio de Ciencia e Innovación (MAT2007-65288, SAF2007-60835), NEUROTRANS 02532006, Complutense University Research Groups UCM-920415 (GR 58/ 08), UCM-920777 (GR 58/08) and Complutense University PR1/0714890 .

Submitted for publication June 22, 2010; revised September 21, 2010; accepted October 14, 2010.

Disclosure: V. Andrés-Guerrero, None; I.T. Molina-Martínez, None; A. Peral, None; B. de las Heras, None; J. Pintor, None; $\mathbf{R}$ Herrero-Vanrell, None

Corresponding author: Rocío Herrero-Vanrell, Department of Pharmacy and Pharmaceutical Technology, Faculty of Pharmacy, Complutense University, 28040, Madrid, Spain;

rociohv@farm.ucm.es
G laucoma is a group of eye diseases characterized by atrophy of the optic nerve and loss of retinal ganglion cells, which leads to a loss of visual acuity and visual field. This disease is the second leading cause of blindness in the world, and it is expected that the number of people who have it will increase dramatically by 2020 to 79.6 million people. ${ }^{1}$

Most forms of glaucoma are related to high intraocular pressure (IOP) values. In these cases the goal of treatments is to control the IOP and prevent further damage to the optic nerve and visual loss. Treatments can only delay the progression of the disease, but they do not cure glaucoma, and so the hypotensive therapy must be continued throughout the lifetime of the patient. The majority of patients undergo the instillation of eye drops one to two times per day, and it is not unusual to find therapies that combine two or more drugs, which can often lead to reduced patient compliance. ${ }^{2-4}$ Allergic reactions and adverse effects associated with chronic glaucoma treatment have been described. ${ }^{5,6}$ These secondary effects are usually related to the drug or other components present in the formulation (mainly preservatives) that can damage the ocular surface in long-term therapies. ${ }^{7-10}$

Many attempts have been made to solve these problems. Because the presence of preservatives increases the toxicity of the formulations, ${ }^{11-14}$ one of the most promising strategies is the development of new formulations with no preservatives in their composition; in fact, it is possible to find some of these formulations on the market today. ${ }^{15}$ Nevertheless, preservatives are able to enhance the active compounds' penetration and, subsequently, their efficacy in many cases. ${ }^{16}$ Therefore, their use is ultimately still maintained in most eye drop formulations. Other options to avoid multiple applications include the use of combinations of already commercialized hypotensive agents ${ }^{17-20}$ or the search for novel active substances with high ocular hypotensive efficacy and low adverse effects on the eye. ${ }^{21-24}$ In addition, several strategies have been developed to increase the bioavailability of topical antiglaucoma drugs by prolonging the contact time of the drug on the ocular surface. ${ }^{25-27}$ Cellulose polymers are very popular and are used for artificial tear solutions and as enhancers of ophthalmic vehicles' viscosity, in a manner that reduces the drainage rate of the drug from the eye and subsequently improves the therapeutic efficacy. ${ }^{28-30}$

Optimization of antiglaucoma therapy requires the discovery of new hypotensive agents and vehicles that are tolerated well by the ocular surface. There are several research groups working on new agents that would be suitable for glaucoma treatment. $^{31-34}$ In the current experimental work, the new active substance object of study is a melatonin receptor agonist 5-MCA-NAT.

Melatonin is a neurohormone whose synthesis takes place primarily in the pineal gland. ${ }^{35-37}$ Local synthesis of melatonin also occurs in the eye of most of the animals species including 
humans. ${ }^{38,39}$ As in the pineal gland, retinal melatonin content significantly changes during the 24-hour cycle, with a peak concentration occurring at night. ${ }^{40}$ Studies in humans revealed a diurnal rhythmicity of IOP with the highest level occurring during daytime and the lowest at night, ${ }^{41-44}$ when melatonin levels increase. In view of this relation, it has been suggested that melatonin influences IOP rhythm. ${ }^{38}$

5-Methoxy-carbonylamino- $N$-acetyltryptamine (5-MCA-NAT) is described as an $\mathrm{MT}_{3}$ melatonin receptor agonist, although there is still some controversy about the identification of its binding site. ${ }^{45-48}$ 5-MCA-NAT has been demonstrated to reduce IOP in glaucomatous monkeys ${ }^{49}$ and in New Zealand White rabbits. ${ }^{50}$ Consequently, it has been regarded as a potential substance for the treatment of ocular hypertension, which is associated with glaucoma. In this work, we prepared several formulations containing 5-MCA-NAT and bioadhesive polymers. The polymers used as vehicles were carboxymethyl cellulose low viscosity $(0.5 \%$ and $1.0 \%)$, carboxymethyl cellulose medium viscosity ( $0.5 \%$ and $1.0 \%)$, and hydroxypropylmethyl cellulose $(0.3 \%)$. The active substance was first dissolved in propylene glycol, which is recognized by the U.S. Food and Drug Administration (FDA) as an ophthalmic demulcent. ${ }^{51}$ We evaluated the improvement of the hypotensive effect of 5-MCA-NAT by these polymers after instillation in rabbit eyes.

\section{Materials ANd Methods}

\section{Compounds}

5-MCA-NAT was provided by Tocris Bioscience (Ellisville, MO) and 1,2-propylene glycol (PG) by Guinama (Valencia, Spain). Carboxymethyl cellulose low viscosity (CMC1; 25-50 cps, 2\% solution at $20^{\circ} \mathrm{C}$ ), carboxymethyl cellulose medium viscosity (CMC2; 400-800 cps, $2 \%$ solution at $20^{\circ} \mathrm{C}$ ), and hydroxypropylmethyl cellulose (HPMC; $1390 \mathrm{cps}, 2 \%$ solution at $20^{\circ} \mathrm{C}$ ) were purchased from Abaran Materias Primas SL (Madrid, Spain). Phosphate-buffered saline (PBS) isotonized with $\mathrm{NaCl}$ ( $\mathrm{pH}$ 7.2) was prepared with ultrapure water (milliQ; Millipore Ibérica SA, Madrid, Spain). Oxybuprocaine-tetracaine anesthetic was obtained from Alcon Cusi SA (Barcelona, Spain).

\section{HPLC Determinations of 5-MCA-NAT}

The analyses were performed with an HPLC instrument (Gilson, Madrid, Spain), with a solvent delivery pump (model 305), a detector (model 118 UV-Vis), and controller software (UniPoint; all by Gilson). The injector was equipped with a $20-\mu \mathrm{L}$ loop (7125 Rheodyne; Gilson). The chromatographic separation was achieved in a reversed-phase protocol with a $\mathrm{C}_{18}$ column $(25 \mathrm{~cm} \times 4 \mathrm{~mm}, 5-\mu \mathrm{m}$ particle size; Mediterranean Sea column; Teknokroma, Barcelona, Spain). The mobile phase was a mixture of $40 \%$ methanol (Panreac, Barcelona, Spain) and $60 \%$ ultrapure (milliQ; Millipore) water. The flow rate was set at $0.8 \mathrm{~mL} / \mathrm{min}$, and the eluent was monitored at $244 \mathrm{~nm}^{22}$

\section{Preparation of Formulations}

Stock solutions of 5-MCA-NAT were prepared by dissolving $10 \mathrm{mg}$ of 5-MCA-NAT in $1 \mathrm{~mL}$ of PG. The resulting solutions $(10 \mathrm{mg} / \mathrm{mL})$ were then diluted with the corresponding vehicle, to give a drug concentration of $100 \mu \mathrm{M}$ and a final percentage of PG of $0.275 \%$. The vehicles used were CMC1, CMC2, and HPMC. All the polymers were dissolved in isotonic PBS ( $\mathrm{pH} 7.2$ ) and diluted to give a final concentration of $0.5 \%$ (CMC1 and CMC2), 1\% (CMC1 and CMC2), or $0.3 \%$ (HPMC). The adjustment of tonicity was performed with sodium chloride. In all cases, the vehicles were sterilized first by filtration $(0.20-\mu \mathrm{m}$ filter pore) and then by autoclaving $\left(121^{\circ} \mathrm{C}, 20\right.$ minutes). All the procedures were performed under aseptic conditions.
The dose of 5-MCA-NAT in formulations was quantified by HPLC under the conditions described earlier.

\section{Characterization of Formulations: Surface Tension and $\mathrm{pH}$}

The surface tension of each formulation was determined by the plate method (PL21; Krüss, Hamburg, Germany), with a digital tensiometer (model K11; Krüss, Hamburg, Germany) in combination with the integrated software (Laboratory Desktop software, ver. 3.11; Krüss) at $33 \pm 0.2^{\circ} \mathrm{C}$ (corneal surface temperature ${ }^{52,53}$ ). The plate was immersed in the solution (speed of $8 \mathrm{~mm} / \mathrm{min}$ ) to a depth of $2.0 \mathrm{~mm}$. Before each measurement, the tensiometer was calibrated with doubledistilled water $(72 \pm 0.5 \mathrm{mN} / \mathrm{m})$. The time required for equilibration of the formulations was set to 3 minutes. The formulations were assayed in triplicate, and the measurements were repeated three times for every formulation.

$\mathrm{pH}$ measurements of formulations were performed at room temperature $\left(25^{\circ} \mathrm{C}\right)$ with a $\mathrm{pH}$ meter (model GLP 21 ; Crison, Barcelona, Spain) equipped with a combined $\mathrm{Ag} / \mathrm{AgCl}$ glass electrode (model 52-02; Crison).

\section{Viability Assays}

The viability assays were performed with immortalized human corneallimbal epithelial cells (HCLE cells; Schepens Eye Research Institute, Harvard Medical School, Boston, MA) and normal human conjunctival cells (IOBA-NHC; Instituto de Oftalmobiología Aplicada, Valladolid University, Valladolid, Spain).

Cytotoxicity studies were assessed by the mitochondrial-dependent reduction of the tetrazolium salt (3-(4,5-dimethylthiazol-2-yl)-2,5-diphenyltetrazolium bromide) to formazan (MTT method ${ }^{5,55}$ ).

HCLE cell cultures were plated in 15-mL culture flasks in a keratinocyte serum-free medium $^{56}$ (SFM), a medium nutritionally optimized for proliferation of keratinocytes, supplemented with $0.5 \mathrm{~mL} \mathrm{CaCl} \mathrm{Ca}_{2} 0.3$ M, $1.25 \mathrm{~mL}$ bovine pituitary extract and $40 \mu \mathrm{L}$ epidermal growth factor (EGF). Cultures were grown at $37^{\circ} \mathrm{C}$ in a $5 \%$ carbon dioxide atmosphere. To inactivate trypsin, this mixture was neutralized with the same volume of Dulbecco's modified Eagle's medium: nutrient mixture F-12 (DMEM/F12) that contained 10\% calf serum and 2\% penicillin/ streptomycin. All reagents were purchased from Invitrogen-Gibco (Barcelona, Spain). The mixture was centrifuged (3000 rpm, for 4 minutes at room temperature), and finally, the cells were resuspended in SFM.

IOBA-NHC cells were plated at $15-\mathrm{mL}$ culture flasks in DMEM/F-12 medium supplemented with $10 \%$ calf serum, $2 \%$ penicillin-streptomycin, $2.5 \mu \mathrm{g} / \mathrm{mL}$ amphotericin $\mathrm{B}, 1 \mu \mathrm{g} / \mathrm{mL}$ bovine pancreas insulin, 0.5 $\mu \mathrm{g} / \mathrm{mL}$ hydrocortisone, $0.1 \mu \mathrm{g} / \mathrm{mL}$ cholera toxin, and $0.2 \mathrm{ng} / \mathrm{mL}$ EGF. Cultures were grown at $37^{\circ} \mathrm{C}$ in a $5 \%$ carbon dioxide atmosphere. The mixture was neutralized with the same volume of DMEM/F12, which contained $10 \%$ calf serum and $2 \%$ penicillin-streptomycin. Then it was centrifuged (1000 rpm, for 5 minutes at room temperature) and finally, the cells were resuspended in culture medium. All reagents were purchased from Invitrogen-Gibco.

For the cytotoxicity studies, cells were seeded into 96-well culture plates $\left(50,000\right.$ cells/well). After adhering to plates $\left(37^{\circ} \mathrm{C}\right.$ for 24 hours in an atmosphere of $5 \% \mathrm{CO}_{2} / 95 \%$ air), the medium was removed and the testing formulation was added. ${ }^{57}$

Cell lines were exposed to (1) formulations with 5-MCA-NAT (100 $\mu \mathrm{M})$ and the corresponding vehicle (CMC1 0.5\%, CMC1 1.0\%, CMC2 $0.5 \%$, CMC2 $1.0 \%$, HPMC $0.3 \%$, or PBS) and (2) vehicles without 5-MCA-NAT. All the formulations (with and without 5-MCA-NAT) contained PG (0.275\%).

The exposure time of cells to formulations was set at 15 minutes, 1 hour, and 4 hours to simulate short- and long-term treatments. After that, the media were carefully removed, and the MTT solution (5 $\mathrm{mg} / \mathrm{mL}$ in PBS) was added to the plates, which were then incubated for 3 hours at $37^{\circ} \mathrm{C}$. After careful aspiration of the MTT solution, the cells were solubilized in DMSO (100 $\mu \mathrm{L} /$ well). MTT and DMSO were purchased from Sigma-Aldrich (Madrid, Spain). The extent of the reduc- 
TABLE 1. Experimental Concentrations Obtained for Formulations with 5-MCA-NAT

\begin{tabular}{llc}
\hline Vehicle & & Experimental Results $(\boldsymbol{\mu g} / \mathbf{m L})$ \\
\hline CMC1 & $0.5 \%$ & $27.59 \pm 0.39$ \\
& $1 \%$ & $27.80 \pm 0.19$ \\
CMC2 & $0.5 \%$ & $27.25 \pm 0.41$ \\
& $1 \%$ & $27.93 \pm 0.21$ \\
HPMC & $0.3 \%$ & $28.02 \pm 0.41$ \\
PBS & & $27.50 \pm 0.15$
\end{tabular}

$n=3$. Data are expressed as micrograms per milliliter. Initial solutions of 5-MCA-NAT in PG $(10 \mathrm{mg} / \mathrm{mL})$ were always used to prepare the formulations. All formulations contained PG $0.275 \%$. The theoretical concentration of 5-MCA-NAT was $27.53 \mu \mathrm{g} / \mathrm{mL}$

tion of MTT to formazan within the cells was quantified by measuring the optical density at $550 \mathrm{~nm}$ with a plate reader (model 6010152EU; Digiscan, Eugendorf, Austria). Viability was set as $100 \%$ in untreated cells. A solution of benzalkonium chloride $0.005 \%$ (BAK; Sigma-Aldrich) was used as the positive control. ${ }^{58,59}$ Cytotoxicity data were obtained from three different experiments by testing seven wells per sample.

\section{Animals}

Male New Zealand White rabbits, weighing 3 to $4 \mathrm{~kg}$, were used. The animals were kept in individual cages with free access to food and water. They were maintained in controlled 12 hour-12 hour light- dark cycles. All the protocols herein complied with the ARVO Statement for the Use of Animals in Ophthalmic and Vision Research and were in accordance with the European Communities Council Directive (86/ 609/EEC).

\section{Intraocular Pressure Measurements}

Intraocular pressure (IOP) was measured by means of a contact tonometer (TonoPenXL; Medtronic Ibérica, Madrid, Spain). Since the application of the tonometer may produce discomfort in the rabbits, the corneas were anesthetized before each measurement. To avoid the dilution of the formulation that the use of the anesthetic might produce, the instillation of the formulation was made 5 minutes after the application of the anesthetic. The anesthetic used was a dilution 1:10 in PBS ( $\mathrm{pH} 7.4)$ of the mixture oxybuprocaine-tetracaine $(4: 1 \mathrm{mg} / \mathrm{mL}$ respectively). For any of the formulations the instillation volume was $25 \mu \mathrm{L}$. As a control, rabbits received formulations without the hypotensive agent 5-MCA-NAT.

To study the time-course of the effect of the formulations, two IOP measurements were taken before any compound was administered (30 minutes and just before the instillation). Then, measurements were taken once every hour over a period of 8 hours.

\section{Short-Term Tolerance of the Drug}

To evaluate the in vivo short-term tolerance of 5-MCA-NAT in the formulations used, $25 \mu \mathrm{L}$ of each formulation was applied to the right eye of male New Zealand White rabbits. As the control, the contralateral eye of each animal received the same volume of vehicle. To determine the tolerance, photographs were taken at every observation time and each eye was compared to the contralateral eye. Examination of the eyes was performed by means of biomicroscopy and specular microscopy (slit lamp SL-8Z; Topcon, Barcelona, Spain). The observations were performed before the instillation of any substance, just after instillation, 2 hours and 6 hours later. The elements that were studied were pupillary reflex; pupil size; superior and inferior eyelids; the presence of redness, blepharitis, and blepharospasm; tear charge; exudates; fluorescein tear film break-up time (TBUT); redness of the bulbar, limbal, and tarsal conjunctival surfaces; inflammation of the nictitating membrane; and transparency of the cornea. Ocular signs were graded according to the Efron scale for contact lens complications. ${ }^{60,61}$

\section{Statistical Analysis}

Data are expressed as the mean $\pm \operatorname{SEM}(n>3$, indicated in each case). Significant differences between two mean values were evaluated by two-tailed Student's $t$-test. If necessary, an analysis of variance (ANOVA) was used. Results were taken as significantly different at $P<$ 0.05 .

The plotting and fitting of dose-response curves was performed with commercial software (OriginPro 8 SR2; Originlab, Northampton, MA).

\section{Results}

\section{Determination of the Dose of 5-MCA-NAT in Formulations}

The HPLC method of quantifying 5-MCA-NAT was validated with respect to linearity, accuracy, and reliability in the range of concentrations between 5 and $50 \mu \mathrm{g} / \mathrm{mL}$. The retention time of 5-MCA-NAT was $10.66 \pm 0.54$ minutes.

The chromatographic method separated CMC1, CMC2, and HPMC from 5-MCA-NAT. In all cases, the retention time of the vehicles was found to be smaller ( $\leq 2.5$ minutes) than the one obtained for 5-MCA-NAT. Results are summarized in Table 1.

In all cases, nonsignificant differences $(P>0.05)$ were observed between the theoretical concentration of 5-MCA-NAT and the experimental values obtained for the formulations. Taking into account that the instillation volume of the formulations in rabbit eyes was $25 \mu \mathrm{L}$, the administered dose of 5-MCA-NAT was $0.693 \pm 0.01 \mu \mathrm{g}$.

\section{Characterization of Formulations}

The resulting data for surface tension and $\mathrm{pH}$ are shown in Table 2 . All the formulations were nearly neutral, but they showed $\mathrm{pH}$ significantly lower than the corresponding value of PBS $(P<0.001$ in all cases $)$.

Surface tension of PBS (solvent of the formulations) was measured and used as a reference. No significant differences were found between the surface tension achieved with PBS $(71.13 \pm 0.5 \mathrm{mN} / \mathrm{m})$ and that obtained with ultrapure water ( $72 \pm 0.5 \mathrm{mN} / \mathrm{m} ; P=0.095)$. On the other hand, the surface tension for the rest of the formulations (with 5-MCA-NAT, PG, and the corresponding vehicles) were significantly lower than the reference in all cases $(P<0.001)$. The result obtained for 5-MCA-NAT/PBS $(64.67 \pm 1.6 \mathrm{mN} / \mathrm{m})$ was found to be the closest to PBS, whereas the formulation 5-MCA-NAT/CMC2 $1.0 \%$ achieved the lowest value $(46.51 \pm 1.64 \mathrm{mN} / \mathrm{m})$.

TABle 2. Physicochemical Parameters of the Formulations of 5-MCA-NAT $100 \mu \mathrm{M}, \mathrm{PG} 0.275 \%$, and the Vehicles Dissolved in Isotonic PBS

\begin{tabular}{lccc}
\hline Vehicle & Concentration & pH (SD) & $\begin{array}{c}\text { Surface Tension } \\
\mathbf{m N} / \mathbf{m} \text { (SD) }\end{array}$ \\
\hline CMC1 & $0.50 \%$ & $7.07(0.03)$ & $60.26(0.380)$ \\
& $1.00 \%$ & $7.02(0.02)$ & $53.89(2.474)$ \\
CMC2 & $0.50 \%$ & $7.05(0.01)$ & $49.87(0.652)$ \\
& $1.00 \%$ & $7.07(0.03)$ & $46.51(1.641)$ \\
HPMC & $0.30 \%$ & $7.09(0.01)$ & $49.42(3.769)$ \\
PBS & & $7.06(<0.01)$ & $64.67(1.614)$ \\
\hline
\end{tabular}

Each value is the mean \pm SD of three determinations. PBS $\mathrm{pH}$ 7.2. 
TABLE 3. HCLE Cell Viability with the Formulations of 5-MCA-NAT $100 \mu \mathrm{M}, \mathrm{PG}(0.275 \%)$, and the Vehicles

\begin{tabular}{lcrrr}
\hline Vehicle & & 15 Minutes & 1 Hour & 4 Hours \\
\hline CMC1 & $0.50 \%$ & $95.37(4.1)$ & $101.06(3.8)$ & $93.77(7.9)$ \\
& $1.00 \%$ & $99.98(2.5)$ & $98.09(4.7)$ & $91.68(5.6)$ \\
CMC2 & $0.50 \%$ & $97.94(3.0)$ & $93.30(6.9)$ & $88.14(9.4)$ \\
& $1.00 \%$ & $97.12(4.5)$ & $91.98(4.1)$ & $83.56(5.7)$ \\
HPMC & $0.30 \%$ & $97.26(4.5)$ & $94.83(5.8)$ & $89.03(6.1)$ \\
PBS & & $97.05(5.3)$ & $96.48(3.3)$ & $91.79(9.5)$ \\
BAK & $0.005 \%$ & $83.3(7.0)$ & $67.8(3.9)$ & $18.7(4.9)$ \\
\hline
\end{tabular}

Data are the percentage (CV) of live HCLE cells. A solution of benzalkonium chloride (BAK, $0.005 \%$ ) was used as the positive control.

\section{Viability Assays}

To simulate chronic therapies in which the formulations are in contact with the ocular surface for short and long periods, the cells were exposed to formulations for 15 minutes (short-term exposure) and 1 and 4 hours (long-term exposures). The cell lines were exposed to formulations with and without 5-MCA-NAT. None of the formulations were cytotoxic to HCLE or IOBA-NHC cells, with both lines showing cell viability higher than $80 \%$. Since no significant differences were found between the two types of formulations (with and without 5-MCA-NAT, $P>0.05$ in all cases), data concerning formulations without the active substance are not shown. Results regarding formulations with 5-MCA-NAT are shown in Tables 3 and 4 .

\section{Effect of 5-MCA-NAT on Rabbit IOP}

Ten independent experiments ( $n=10$ rabbits) were performed to evaluate the hypotensive effect of each formulation. Solutions without 5-MCA-NAT were used as control. Every day, only a single dose was tested on a single animal and a washout period of at least 48 hours between experiments was allowed. All the vehicles containing 5-MCA-NAT were able to maintain the hypotensive effect of 5-MCA-NAT providing different maximum effects, as is shown in Table 5 and Figures 1 and 2. Data regarding the maximum percentage of IOP reduction are shown in Table 6.

The minimum percentage of IOP reduction was found with CMC $10.5 \%(13.80 \%)$ and the maximum with CMC2 $0.5 \%$ (30.27\%). Taking the formulation 5-MCA-NAT dissolved in PBS as a reference (18.11\% IOP reduction), significant differences in the maximum hypotensive effect were obtained between PBS, CMC1 0.5\% $(P=0.01)$, and CMC2 0.5\% $(P<0.0001)$. On the contrary, no significant differences were found when the maximum IOP reduction of the reference formulation was compared with CMC1 1.0\% $(P=0.29)$, CMC2 1.0\% $(P=0.21)$, and HPMC $0.3 \%(P=0.15)$.

Data regarding the area under the $\Delta I O P(\%)$-time curve from 0 to 8 hours (AUC) are shown in Table 5. The AUC of the reference formulation (5-MCA-NAT/PBS) was significantly lower than the values obtained for formulations with CMC1 $0.5 \%$ and with CMC2 $0.5 \%(P=0.02$ and $P=0.0003$, respectively). However, there were no significant differences in the AUCs for the formulations with CMC1 1.0\% $(P=0.98)$, CMC2 1.0\% $(P=0.19)$, and HPMC 0.3\% $(P=$ $0.18)$.

The mean time effect, which is a term used to define the average duration of the hypotensive effect, was considered to be the period in which the IOP value was at or below half of the maximum value achieved in the experiment. The formulation composed of 5-MCA-NAT and PBS (reference formulation) produced an effect that lasted approximately 6 hours. This effect was exceeded only by the formulation that contained the bioadhesive agent CMC2 $0.5 \%$, which lasted approximately 7 hours (Table 5).

\section{Short-Term Tolerance Evaluation}

The images taken with the specular microscope, both before and after instillation, showed a uniform distribution of the corneal endothelial cells in size and shape for all the formulations. The cellular distribution was within the expected range for rabbit corneas (2000-2500 cells $\left./ \mathrm{mm}^{2}\right)$.

The study performed by means of the slit lamp showed a slight redness in the free margins of the eyelids just before instillation in all cases, as a natural state of the rabbit eyes (Table 7).

None of the vehicles produced irritation or discomfort in the rabbit eyes up to 6 hours after administration. Tearing, redness, and blepharospasm were not visible with any formulation.

\section{Discussion}

The present experimental work describes the ocular hypotensive effect of six formulations containing 5-MCA-NAT, a melatonin receptor agonist and different cellulose derivatives used as vehicles (carboxymethyl- and hydroxypropylmethyl cellulose). We obtained formulations that were demonstrated to be well tolerated by the ocular surface. In addition, the polymers present in some of the formulations increased the hypotensive effect of 5-MCA-NAT.

Glaucoma is a chronic disease that commonly leads to loss of visual acuity and visual field. Most forms of glaucoma are associated with high IOPs; in these cases, chronic therapies with hypotensive agents are mandatory. Antiglaucoma medications are frequently associated with some adverse effects, such

TABLE 4. OBA-NHC Viability for the Formulations with 5-MCA-NAT $100 \mu \mathrm{M}, \mathrm{PG}(0.275 \%)$, and the Vehicles

\begin{tabular}{lllll}
\hline Vehicle & & 15 Minutes & 1 Hour & 4 Hours \\
\hline CMC1 & $0.50 \%$ & $96.45(5.40)$ & $97.57(8.29)$ & $98.47(8.11)$ \\
& $1.00 \%$ & $94.30(5.75)$ & $91.54(4.76)$ & $92.40(5.29)$ \\
CMC2 & $0.50 \%$ & $90.62(3.28)$ & $91.34(8.81)$ & $91.88(8.77)$ \\
& $1.00 \%$ & $91.50(2.09)$ & $87.84(4.28)$ & $88.38(2.63)$ \\
HPMC & $0.30 \%$ & $86.83(3.42)$ & $86.19(6.81)$ & $87.10(5.43)$ \\
PBS & & $98.41(2.72)$ & $94.35(6.94)$ & $95.27(5.60)$ \\
BAK & $0.005 \%$ & $82.01(7.0)$ & $42.29(5.9)$ & $20.95(4.9)$ \\
\hline
\end{tabular}

Data are the percentage (CV) of viable IOBA-NHC cells. A solution of benzalkonium chloride (BAK, $0.005 \%)$ was used as the positive control. 
TABLE 5. Eight-Hour Time Course of the Ocular Hypotensive Effect of Six Formulations with 5-MCA-NAT, PG (0.275\%), and the Vehicles or PBS

\begin{tabular}{|c|c|c|c|c|c|c|}
\hline Time (h) & CMC1 0.5\% & CMC1 1.0\% & CMC2 $0.5 \%$ & CMC2 1.0\% & HPMC $0.3 \%$ & PBS \\
\hline-0.5 & 100.00 & 100.00 & 100.00 & 100.00 & 100.00 & 100.00 \\
\hline 0 & 100.00 & 100.00 & 100.00 & 100.00 & 100.00 & 100.00 \\
\hline 1 & $94.60 \pm 7.60$ & $85.17 \pm 7.51$ & $77.52 \pm 7.02$ & $88.38 \pm 7.57$ & $91.34 \pm 8.52$ & $86.16 \pm 6.75$ \\
\hline 2 & $88.99 \pm 3.13$ & $82.00 \pm 6.39$ & $76.95 \pm 3.04$ & $85.89 \pm 6.30$ & $89.03 \pm 5.51$ & $86.98 \pm 5.47$ \\
\hline 3 & $87.10 \pm 4.37$ & $86.50 \pm 5.41$ & $77.09 \pm 6.86$ & $86.52 \pm 5.78$ & $87.38 \pm 4.43$ & $85.59 \pm 5.71$ \\
\hline 4 & $88.05 \pm 2.35$ & $87.82 \pm 3.99$ & $80.55 \pm 3.10$ & $89.14 \pm 5.37$ & $93.04 \pm 6.80$ & $87.03 \pm 4.25$ \\
\hline 5 & $95.85 \pm 4.92$ & $88.59 \pm 5.51$ & $80.96 \pm 8.85$ & $90.80 \pm 8.10$ & $93.20 \pm 4.72$ & $84.51 \pm 6.10$ \\
\hline 6 & $91.96 \pm 6.19$ & $90.48 \pm 7.37$ & $85.21 \pm 5.64$ & $94.88 \pm 6.27$ & $89.22 \pm 6.50$ & $91.05 \pm 6.10$ \\
\hline 7 & $100.66 \pm 7.33$ & $97.51 \pm 4.44$ & $87.20 \pm 6.04$ & $95.72 \pm 6.73$ & $91.45 \pm 5.74$ & $93.98 \pm 5.29$ \\
\hline 8 & $99.66 \pm 6.57$ & $97.51 \pm 4.45$ & $91.81 \pm 7.58$ & $95.72 \pm 6.55$ & $91.45 \pm 5.65$ & $98.72 \pm 7.20$ \\
\hline
\end{tabular}

Data are represented as mean percentage \pm SD of 10 determinations. Bold data represent the mean time (hours) in which the duration of the effect is maintained (mean time effect).

as allergic reactions, allergic contact dermatitis, or punctate corneal staining. ${ }^{62}$ Moreover, several studies have demonstrated that dry eye syndrome ${ }^{63-65}$ or damage of the corneal epithelium ${ }^{66,67}$ are usual after the long-term administration of topical antihypertensive agents.

The ocular toxicity of topical treatments is frequently associated with the preservative used in the formulation.
Most of preservatives have been described to increase macrophages, lymphocytes, and fibroblasts in the conjunctiva and Tenon capsule. ${ }^{68}$ Furthermore, they can also destabilize the tear film indirectly by decreasing the density of goblet cells in the conjunctival epithelium compromising the ability of the tear film to provide protection and trophic factors to the cornea. ${ }^{69}$ In the particular case of benzalkonium
FigURE 1. Ocular hypotensive effect of 5-MCA-NAT $100 \mu \mathrm{M}$ in six different vehicles: (a) PBS, (b) CMC1 $0.5 \%$, (c) $\mathrm{CMC} 11.0 \%$, (d) $\mathrm{CMC} 2$ $0.5 \%$, (e) CMC2 $1.0 \%$, and (f) HPMC $0.3 \%$. The corresponding vehicles without 5-MCA-NAT are considered as controls in each case. Data are represented as the mean \pm SEM of 10 determinations.
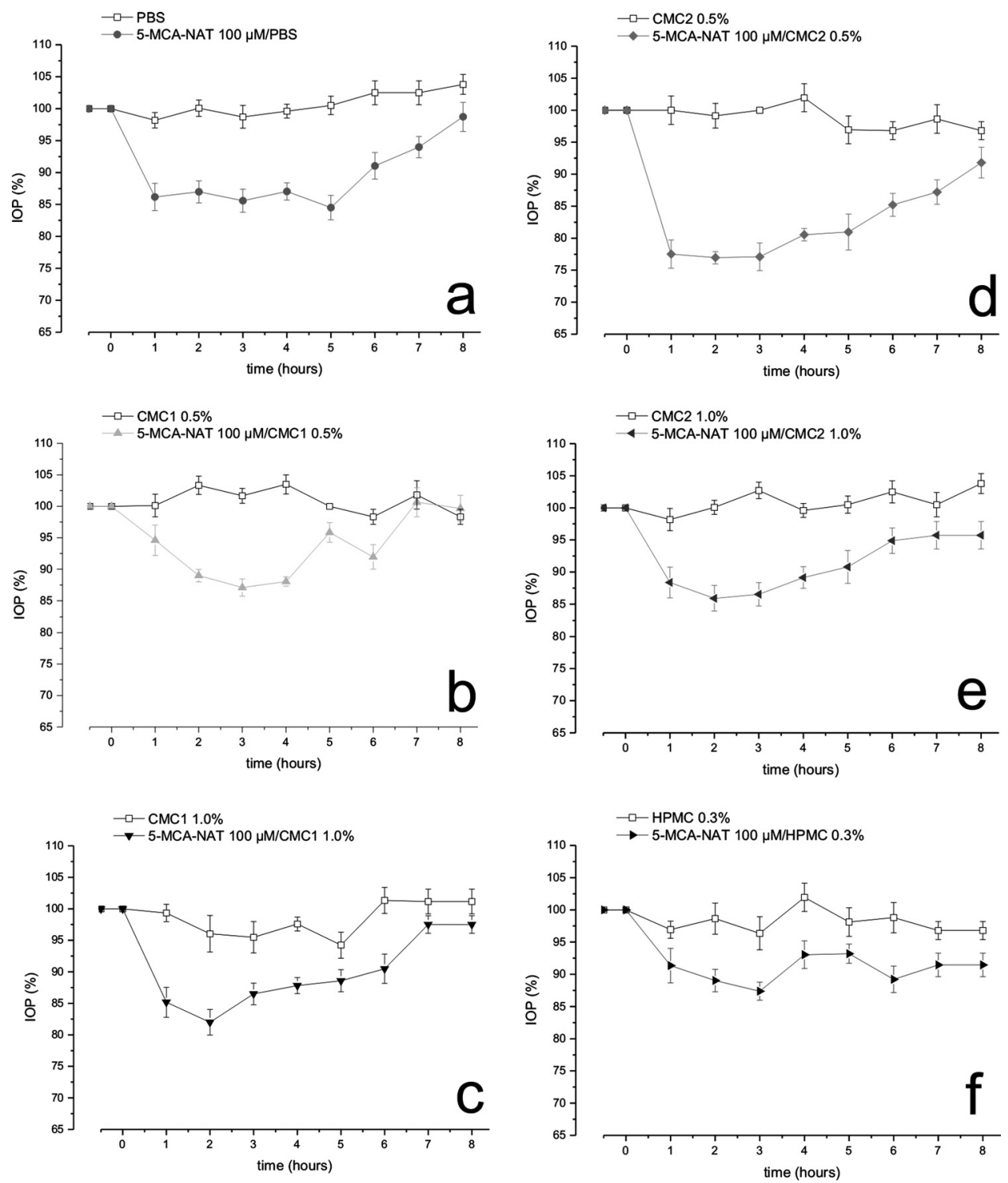


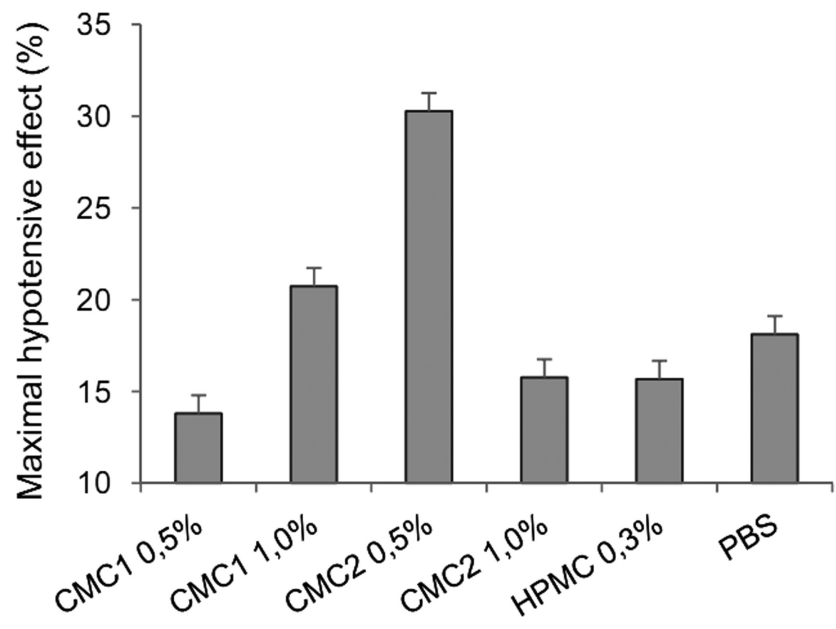

FIGURE 2. Maximum hypotensive effect ( $\% \pm$ SEM) of 5-MCA-NAT $100 \mu \mathrm{M}$ in CMC1 0.5\%, CMC1 1.0\%, CMC2 0.5\%, CMC2 1.0\%, HPMC $0.3 \%$, and PBS.

chloride, damage to the corneal epithelial cells and inhibition of the growth of trabecular meshwork cells have been reported. ${ }^{10}$

In most cases, ocular surface modifications directly impact the effectiveness of long-term therapies. Fechtner et al. ${ }^{70}$ demonstrated that ocular surface disease symptoms in patients with glaucoma using topical IOP-lowering therapy correlates positively with the number of IOP-lowering medications used. From the clinical point of view, the management of patients with glaucoma or ocular hypertension who also have dry eye syndrome must reduce eye drop-induced toxicity as well as develop a specific treatment that is well tolerated by the ocular surface. Extending the limits of tolerance, by improving the tolerability of medications, should become one of the key objectives of glaucoma therapy. Attending to these facts, the employment of polymers that combine good properties for the ocular surface with the ability of increasing the ocular contact time of the formulation is a good strategy for the treatment of glaucoma. Furthermore, the increase in ocular contact time may add to the bioavailability of the drug, that so the drug dosage and the number of instillations could be reduced.

In the present study, IOP-lowering formulations with no preservative in their composition were prepared. Each ingredient of the ophthalmic formulations developed in this work was selected from FDA-approved ophthalmic products. $^{55}$

Before elaborating the formulations, we prepared stock solutions of 5-MCA-NAT in PG. PG is recognized by the FDA as an ophthalmic demulcent that protects and lubricates mucous membrane surfaces and relieves dryness and irritation. Therefore, PG is widely used as a solvent, humectant, and preservative substance in commercial ophthalmic preparations at concentrations ranging between $0.3 \%$ and $1 \%$. In a previous work, ${ }^{22}$ we conducted solubility assays to demonstrate that PG dissolved the drug completely in a concentration of $10 \mathrm{mg} / \mathrm{mL}$. For the final formulations, stock solutions of 5-MCA-NAT in PG were diluted with the vehicle (carboxymethyl cellulose or hydroxypropylmethyl cellulose) to obtain a final PG concentration of $0.275 \%$ and the corresponding percentage of the polymer.

All cellulose ethers impart viscosity to ophthalmic formulations, have wetting properties, and increase the contact time of solutions by virtue of film-forming properties. ${ }^{30,71-75}$ Some of them (e.g., hydroxypropylmethyl cellulose) exhibit surface active properties and interact with components of the tear film, increasing its stability. ${ }^{76}$ Carboxymethyl cellulose also possesses mucoadhesive properties. ${ }^{75}$ It is believed that mucoadhesion takes place when the acidic groups of the bioadhesive polymers link with the sialic moieties present in the mucins of the eye although, at the moment, no theory has successfully explained this mechanism. ${ }^{77}$

The effects of the formulations of 5-MCA-NAT described herein were compared by using the maximum hypotensive effect of the active compound (percentage) the AUC of the $\Delta \mathrm{IOP}$ (percentage) versus time (hours) from 0 to 8 hours, the mean time (hours) in which the duration of the hypotensive effect is maintained, mean time effect, and the lower number of toxic/ secondary effects of the vehicles.

The formulation 5-MCA-NAT $100 \mu \mathrm{M} / \mathrm{PBS}$ produced a maximum IOP reduction of $18.11 \%$, and it was taken as the reference. The hypotensive effect of the active compound increased only when CMC1 $1.0 \%$ or CMC2 $0.5 \%$ was added to the formulation, but it was statistically significantly only for CMC2 $0.5 \%(30.27 \%, P<0.0001)$. The AUC of 5 -MCANAT $100 \mu \mathrm{M} / \mathrm{PBS}$ was significantly lower than the values obtained with CMC1 $0.5 \%$ or CMC2 $0.5 \%(P=0.02$ and 0.0003 , respectively). Concerning the mean time effect, the reference formulation produced an effect that lasted approximately 6 hours. This effect was exceeded only by the formulation that contained CMC2 $0.5 \%$, whose effect lasted approximately 7 hours.

The film-forming and bioadhesive properties of polymers depend on the concentration, and that may be the reason why there were differences among the formulations that we tested. It is evident that there is a range of concentrations for each polymer to provide an improvement of the drug activity. Within the polymers and concentrations that we tested, the formulation containing the bioadhesive polymer CMC2 $0.5 \%$ was the best at lowering IOP in rabbit eyes.

In vitro cytotoxicity studies in human corneal-limbal epithelial cells and normal human conjunctival cells were performed to determine the tolerance of formulations. Taking into account that a conventional topical ophthalmic formulation is eliminated in only 5 minutes from the ocular surface, short contact times (15 minutes) are enough to determine tolerance. Nevertheless, in chronic therapies, such as hypotensive therapies, cells are exposed several times to topical formulations. Moreover, bioadhesive polymers are able to increase the ocular contact time of the formulation in the ocular surface. ${ }^{75}$ Thus, to simulate longer exposures, contact times of 1 and 4 hours were used for the assay. In all cases, formulations did not prove cytotoxic to cells showing cell viability values higher than $80 \%$. Good in vivo short-term tolerance was also demonstrated, as no irritation or discomfort was present in the rabbit eyes with any of the formulations.

In conclusion, we used several formulations containing different bioadhesive polymers to study the hypotensive effect of the melatonin analogue 5-MCA-NAT in rabbit eyes.

TABLE 6. Maximum IOP Reduction Induced by 5-MCA-NAT $100 \mu \mathrm{M}$ in the Vehicles and PBS

\begin{tabular}{lcccc}
\hline Vehicle & & $\begin{array}{c}\text { Maximal IOP } \\
\text { Reduction }\end{array}$ & AUC (0-8 h) & $\begin{array}{c}\text { Mean Time } \\
\text { Effect (h) }\end{array}$ \\
\hline CMC1 & $0.50 \%$ & $13.80 \pm 1.40$ & $86.29 \pm 8.94$ & 5 \\
& $1.00 \%$ & $20.73 \pm 1.74$ & $58.99 \pm 5.84$ & 6 \\
CMC2 & $0.50 \%$ & $30.27 \pm 1.49$ & $138.61 \pm 6.20$ & 7 \\
& $1.00 \%$ & $15.76 \pm 2.13$ & $69.61 \pm 8.65$ & 5 \\
HPMC & $0.30 \%$ & $15.68 \pm 1.20$ & $83.17 \pm 4.23$ & 3 \\
PBS & & $18.11 \pm 1.07$ & $70.81 \pm 11.86$ & 6 \\
\hline
\end{tabular}

$n=10$. Data are the mean percentage \pm SEM. 
TABLE 7. Qualitative Evaluation of Ocular Signs Produced by Six Formulations with 5-MCA-NAT, PG (0.275\%), the Vehicles, and PBS

\begin{tabular}{|c|c|c|c|c|c|c|c|c|c|c|c|c|c|c|c|c|}
\hline \multirow[b]{2}{*}{ Formulations } & \multicolumn{4}{|c|}{ Before Instillation } & \multicolumn{4}{|c|}{ Just after Instillation } & \multicolumn{4}{|c|}{2 Hours Later } & \multicolumn{4}{|c|}{6 Hours Later } \\
\hline & $\mathbf{T}$ & $\mathbf{B}$ & $\mathbf{L}$ & $\mathbf{E}$ & $\mathbf{T}$ & $\mathbf{B}$ & $\mathbf{L}$ & $\mathbf{E}$ & $\mathbf{T}$ & B & $\mathbf{L}$ & $\mathbf{E}$ & $\mathbf{T}$ & B & $\mathbf{L}$ & $\mathbf{E}$ \\
\hline CMC10.5\% & 0 & 0 & $2-3$ & 2 & 0 & 0 & $2-3$ & 2 & 0 & 0 & $2-3$ & 2 & 0 & 0 & 2 & $1-2$ \\
\hline CMC1 1.0\% & 0 & 0 & $2-3$ & $1-2$ & 0 & 0 & $2-3$ & $1-2$ & 0 & 0 & $2-3$ & $1-2$ & 0 & 0 & $2-3$ & $1-2$ \\
\hline СMC20.5\% & 0 & 0 & 2 & 2 & 0 & 0 & 2 & 2 & 0 & 0 & 2 & $1-2$ & 0 & 0 & 2 & $1-2$ \\
\hline CMC21.0\% & 0 & 0 & 2 & 2 & 0 & 0 & 2 & 2 & 0 & 0 & 2 & $1-2$ & 0 & 0 & 2 & $1-2$ \\
\hline HPMC0.3\% & 0 & 0 & 3 & 1 & 0 & 0 & 3 & 1 & 0 & 0 & 3 & 1 & 0 & 0 & $2-3$ & 1 \\
\hline PBS & 0 & 0 & 2 & 1 & 0 & 0 & 2 & 1 & 0 & 0 & 2 & $0-1$ & 0 & 0 & 2 & 1 \\
\hline
\end{tabular}

Six male New Zealand white rabbits were used for the experiments. Each formulation was applied to the right eye of the rabbit. As a control, the contralateral eye of each rabbit received the same volume of vehicle. T, tearing; B, blepharospasm; L limbal conjunctiva redness; and E, tarsal conjunctiva redness, eyelid, were assessed according to the Efron grading scale: 0 , normal; 1 , very slight; 2 , slight; 3 , moderate; and 4, severe.

The polymers that we used (cellulose derivatives) are suitable for use on the ocular surface, are protective of the eye in long-term therapy, and are currently widely used in artificial tear solutions in the treatment of dry eye. Furthermore, we found that the hypotensive effect of 5-MCA-NAT was enhanced with the use of CMC1 $1.0 \%$ and CMC2 $0.5 \%$, the latter being the most effective at reducing IOP (30.27\%). We have developed an optimal formulation with a bioadhesive polymer (CMC) able to increase the hypotensive effect of the active substance while being, at the same time, gentle with the ocular surface. Finally, from the IOP values obtained after the instillation of 5-MCA-NAT in rabbit eyes, we can also conclude that the use of 5-MCA-NAT combined with bioadhesive polymers may be possible in the treatment of ocular hypertension and glaucoma.

\section{References}

1. Quigley HA, Broman AT. The number of people with glaucoma worldwide in 2010 and 2020. Br J Ophthalmol. 2006;90:262267.

2. Curtis C, Lo E, Ooi L, Bennett L, Long J. Factors affecting compliance with eye drop therapy for glaucoma in a multicultural outpatient setting. Contemp Nurse. 2009;31:121-128.

3. Kholdebarin R, Campbell RJ, Jin YP, Buys YM. Multicenter study of compliance and drop administration in glaucoma. Can J Ophthalmol. 2008; 43:454-461.

4. Gray TA, Orton LC, Henson D, Harper R, Waterman H. Interventions for improving adherence to ocular hypotensive therapy. Cochrane Database Syst Rev. 2009;CD006132.

5. Kalavala M, Statham BN. Allergic contact dermatitis from timolol and dorzolamide eye drops. Contact Dermatitis. 2006;54:345.

6. Quiralte J, Florido F, de San Pedro BS. Allergic contact dermatitis from carteolol and timolol in eyedrops. Contact Dermatitis. 2000; 42:245.

7. Camras CB, Toris CB, Tamesis RR. Efficacy and adverse effects of medications used in the treatment of glaucoma. Drugs Aging. 1999; 15:377-388.

8. Martone G, Frezzotti P, Tosi GM, et al. An in vivo confocal microscopy analysis of effects of topical antiglaucoma therapy with preservative on corneal innervation and morphology. Am J Ophthalmol. 2009;147:725-735 e721.

9. Baffa Ldo P, Ricardo JR, Dias AC, et al. Tear film and ocular surface alterations in chronic users of antiglaucoma medications. Arq Bras Oftalmol. 2008;71:18-21.

10. Baudouin C, Riancho L, Warnet JM, Brignole F. In vitro studies of antiglaucomatous prostaglandin analogues: travoprost with and without benzalkonium chloride and preserved latanoprost. Invest Ophthalmol Vis Sci. 2007;48:4123-4128.

11. Bai T, Huang J, Wang W. Short-term comparative study of the effects of preserved and unpreserved topical levofloxacin on the human ocular surface. Cutan Ocul Toxicol. 2010;29:247253.
12. Baudouin C, de Lunardo C. Short-term comparative study of topical $2 \%$ carteolol with and without benzalkonium chloride in healthy volunteers. Br J Ophthalmol. 1998;82:39-42.

13. Kahook MY, Noecker RJ. Comparison of corneal and conjunctival changes after dosing of travoprost preserved with sofzia, latanoprost with $0.02 \%$ benzalkonium chloride, and preservative-free artificial tears. Cornea. 2008;27:339-343.

14. Brasnu E, Brignole-Baudouin F, Riancho L, Guenoun JM, Warnet JM, Baudouin C. In vitro effects of preservative-free tafluprost and preserved latanoprost, travoprost, and bimatoprost in a conjunctival epithelial cell line. Curr Eye Res. 2008;33:303-312.

15. Bartlett JD. Ophthalmic Drug Facts: Facts and Comparisons. 21st ed. Hagerstown, MD: Lippincott Williams \& Wilkins; 2009:371407.

16. Baudouin C, Labbe A, Liang H, Pauly A, Brignole-Baudouin F. Preservatives in eyedrops: the good, the bad and the ugly. Prog Retin Eye Res. 2010;29:312-334.

17. Mundorf T, Noecker RJ, Earl M. Ocular hypotensive efficacy of brimonidine $0.15 \%$ as adjunctive therapy with latanoprost $0.005 \%$ in patients with open-angle glaucoma or ocular hypertension. $A d v$ Ther. 2007;24:302-309.

18. Franks W. Ocular hypotensive efficacy and safety of brinzolamide ophthalmic suspension $1 \%$ added to travoprost ophthalmic solution $0.004 \%$ therapy in patients with open-angle glaucoma or ocular hypertension. Curr Med Res Opin. 2006;22: 1643-1649.

19. Manni G, Denis P, Chew $P$, et al. The safety and efficacy of brinzolamide $1 \%$ /timolol $0.5 \%$ fixed combination versus dorzolamide $2 \% /$ timolol $0.5 \%$ in patients with open-angle glaucoma or ocular hypertension. J Glaucoma. 2009;18:293-300.

20. Martinez A, Sanchez-Salorio M. A comparison of the long-term effects of dorzolamide $2 \%$ and brinzolamide $1 \%$, each added to timolol $0.5 \%$, on retrobulbar hemodynamics and intraocular pressure in open-angle glaucoma patients. J Ocul Pharmacol Ther. 2009;25:239-248.

21. Arnold JJ, Choksi Y, Chen X, et al. Eyedrops containing SA9000 prodrugs result in sustained reductions in intraocular pressure in rabbits. J Ocul Pharmacol Ther. 2009;25:179-186.

22. Andres-Guerrero V, Alarma-Estrany P, Molina-Martinez IT, Peral A, Herrero-Vanrell R, Pintor J. Ophthalmic formulations of the intraocular hypotensive melatonin agent 5-MCA-NAT. Exp Eye Res. 2009;88:504-511.

23. Wang RF, Podos SM, Mittag TW, Yokoyoma T. Effect of CS-088, an angiotensin AT1 receptor antagonist, on intraocular pressure in glaucomatous monkey eyes. Exp Eye Res. 2005;80:629-632.

24. Hosseini A, Lattanzio FA, Williams PB, Tibbs D, Samudre SS, Allen RC. Chronic topical administration of WIN-55-212-2 maintains a reduction in IOP in a rat glaucoma model without adverse effects. Exp Eye Res. 2006;82:753-759.

25. Higashiyama $\mathbf{M}$, Inada $\mathrm{K}$, Ohtori $\mathbf{A}$, Tojo $\mathrm{K}$. Improvement of the ocular bioavailability of timolol by sorbic acid. Int J Pharm. 2004; 272:91-98.

26. von der Ohe N, Stark M, Mayer H, Brewitt $\mathrm{H}$. How can the bioavailability of timolol be enhanced? - a pharmacokinetic pilot 
study of novel hydrogels. Graefes Arch Clin Exp Ophthalmol. 1996;234:452- 456

27. Aggarwal D, Pal D, Mitra AK, Kaur IP. Study of the extent of ocular absorption of acetazolamide from a developed niosomal formulation, by microdialysis sampling of aqueous humor. Int J Pharm. 2007;338:21-26.

28. Saettone MF, Giannaccini B, Teneggi A, Savigni P, Tellini N. Vehicle effects on ophthalmic bioavailability: the influence of different polymers on the activity of pilocarpine in rabbit and man.J Pharm Pharmacol. 1982;34:464-466.

29. Patton TF, Robinson JR. Ocular evaluation of polyvinyl alcohol vehicle in rabbits. J Pharm Sci. 1975;64:1312-1316.

30. Ludwig A. The use of mucoadhesive polymers in ocular drug delivery. Adv Drug Deliv Rev. 2005;57:1595-1639.

31. May JA, Dantanarayana AP, Zinke PW, McLaughlin MA, Sharif NA. 1-((S)-2-aminopropyl)-1H-indazol-6-ol: a potent peripherally acting 5-HT2 receptor agonist with ocular hypotensive activity. $J$ Med Chem. 2006;49:318-328.

32. Markovskaya A, Crooke A, Guzman-Aranguez AI, Peral A, Ziganshin AU, Pintor J. Hypotensive effect of UDP on intraocular pressure in rabbits. Eur J Pharmacol. 2008;579:93-97.

33. Chien FY, Wang RF, Mittag TW, Podos SM. Effect of WIN 55212-2, a cannabinoid receptor agonist, on aqueous humor dynamics in monkeys. Arch Ophthalmol. 2003;121:87-90.

34. Pang $\mathrm{IH}$, Moll H, McLaughlin MA, et al. Ocular hypotensive and aqueous outflow-enhancing effects of AL-3037A (sodium ferri ethylenediaminetetraacetate). Exp Eye Res. 2001;73:815-825.

35. Miguez JM, Recio J, Sanchez-Barcelo E, Aldegunde M. Changes with age in daytime and nighttime contents of melatonin, indoleamines, and catecholamines in the pineal gland: a comparative study in rat and Syrian hamster. J Pineal Res. 1998;25: $106-115$.

36. Arendt J. Melatonin and the pineal gland: influence on mammalian seasonal and circadian physiology. Rev Reprod. 1998;3:13-22.

37. Luboshitzky R, Yanai D, Shen-Orr Z, Israeli E, Herer P, Lavie P Daily and seasonal variations in the concentration of melatonin in the human pineal gland. Brain Res Bull. 1998;47:271-276.

38. Lundmark PO, Pandi-Perumal SR, Srinivasan V, Cardinali DP, Rosenstein RE. Melatonin in the eye: implications for glaucoma. Exp Eye Res. 2007;84:1021-1030.

39. Alarma-Estrany P, Pintor J. Melatonin receptors in the eye: location, second messengers and role in ocular physiology. Pharmacol Ther. 2007;113:507-522.

40. Wiechmann AF, Summers JA. Circadian rhythms in the eye: the physiological significance of melatonin receptors in ocular tissues Prog Retin Eye Res. 2008;27:137-160.

41. Katavisto $M$. The diurnal variations of ocular tension in glaucoma. Acta Ophthalmol Suppl. 1964;78(suppl):71-130.

42. Henkind $P$, Leitman M, Weitzman E. The diurnal curve in man: new observations. Invest Ophthalmol. 1973;12:705-707.

43. Kitazawa Y, Horie T. Diurnal variation of intraocular pressure in primary open-angle glaucoma. Am J Ophthalmol. 1975;79:557566.

44. Ido T, Tomita G, Kitazawa Y. Diurnal variation of intraocular pressure of normal-tension glaucoma: influence of sleep and arousal. Ophthalmology. 1991;98:296-300.

45. Pintor J, Martin L, Pelaez T, Hoyle $\mathrm{CH}$, Peral A. Involvement of melatonin MT(3) receptors in the regulation of intraocular pressure in rabbits. Eur J Pharmacol. 2001;416:251-254.

46. Mailliet F, Ferry G, Vella F, et al. Characterization of the melatoninergic MT3 binding site on the NRH:quinone oxidoreductase 2 enzyme. Biochem Pharmacol. 2005;71:74-88.

47. Alarma-Estrany P, Crooke A, Pintor J. 5-MCA-NAT does not act through NQO2 to reduce intraocular pressure in New-Zealand white rabbit. J Pineal Res. 2009;47:201-209.

48. Vincent L, Cohen W, Delagrange P, Boutin JA, Nosjean O. Molecular and cellular pharmacological properties of 5-methoxycarbonylamino-N-acetyltryptamine (MCA-NAT): a nonspecific MT3 ligand. J Pineal Res. 2010;48:222-229.

49. Serle JB, Wang RF, Peterson WM, Plourde R, Yerxa BR. Effect of 5-MCA-NAT, a putative melatonin MT3 receptor agonist, on intraocular pressure in glaucomatous monkey eyes. J Glaucoma. 2004; $13: 385-388$
50. Pintor J, Pelaez T, Hoyle CH, Peral A. Ocular hypotensive effects of melatonin receptor agonists in the rabbit: further evidence for an MT3 receptor. Br J Pharmacol. 2003;138:831-836.

51. FDA, Ophthalmic demulcents, Part 349.12. Subheading of ophthalmic drug products for over-the-counter human use, 21CFR349 (2006) Available at http://www.fda.gov/downloads/AboutFDA/ CentersOffices/CDER/UCM135691.pdf.

52. Morgan PB, Soh MP, Efron N. Corneal surface temperature decreases with age. Cont Lens Anterior Eye. 1999;22:11-13.

53. Acosta MC, Berenguer-Ruiz L, Garcia-Galvez A, Perea-Tortosa D, Gallar J, Belmonte C. Changes in mechanical, chemical, and thermal sensitivity of the cornea after topical application of nonsteroidal anti-inflammatory drugs. Invest Ophthalmol Vis Sci. 2005;46: 282-286.

54. Scudiero DA, Shoemaker RH, Paull KD, et al. Evaluation of a soluble tetrazolium/formazan assay for cell growth and drug sensitivity in culture using human and other tumor cell lines. Cancer Res. 1988;48:4827-4833.

55. Liu Y, Peterson DA, Kimura H, Schubert D. Mechanism of cellular 3-(4,5-dimethylthiazol-2-yl)-2,5-diphenyltetrazolium bromide (MTT) reduction. J Neurochem. 1997;69:581-593.

56. Gipson IK, Spurr-Michaud S, Argueso P, Tisdale A, Ng TF, Russo CL. Mucin gene expression in immortalized human corneal-limbal and conjunctival epithelial cell lines. Invest Ophthalmol Vis Sci. 2003; 44:2496-2506

57. Saarinen-Savolainen $\mathrm{P}$, Jarvinen T, Araki-Sasaki K, Watanabe H, Urtti A. Evaluation of cytotoxicity of various ophthalmic drugs, eye drop excipients and cyclodextrins in an immortalized human corneal epithelial cell line. Pharm Res. 1998;15:12751280.

58. Wilson WS, Duncan AJ, Jay JL. Effect of benzalkonium chloride on the stability of the precorneal tear film in rabbit and man. $\mathrm{Br} \mathrm{J}$ Ophthalmol. 1975;59:667-669.

59. De Saint Jean M, Brignole F, Bringuier AF, Bauchet A, Feldmann G, Baudouin C. Effects of benzalkonium chloride on growth and survival of Chang conjunctival cells. Invest Ophthalmol Vis Sci. 1999; 40:619-630.

60. Efron N. Grading scales for contact lens complications. Ophthalmic Physiol Opt. 1998;18:182-186.

61. Efron N, Morgan PB, Katsara SS. Validation of grading scales for contact lens complications. Ophthalmic Physiol Opt. 2001;21:1729.

62. Guenoun JM, Baudouin C, Rat P, Pauly A, Warnet JM, BrignoleBaudouin $F$. In vitro study of inflammatory potential and toxicity profile of latanoprost, travoprost, and bimatoprost in conjunctivaderived epithelial cells. Invest Ophthalmol Vis Sci. 2005;46:24442450.

63. Detry-Morel M. Side effects of glaucoma medications. Bull Soc Belge Opbtalmol. 2006;27-40.

64. Baudouin C, Liang H, Hamard P, et al. The ocular surface of glaucoma patients treated over the long-term expresses inflammatory markers related to both T-helper 1 and T-helper 2 pathways. Ophthalmology. 2008;115:109-115.

65. Rossi GC, Tinelli C, Pasinetti GM, Milano G, Bianchi PE. Dry eye syndrome-related quality of life in glaucoma patients. Eur J Ophthalmol. 2009;19:572-579.

66. Ayaki M, Yaguchi S, Iwasawa A, Koide R. Cytotoxicity of ophthalmic solutions with and without preservatives to human corneal endothelial cells, epithelial cells and conjunctival epithelial cells. Clin Exp Ophthalmol. 2008;36:553-559.

67. Schuman JS. Antiglaucoma medications: a review of safety and tolerability issues related to their use. Clin Ther. 2000;22:167-208.

68. Sherwood MB, Grierson I, Millar L, Hitchings RA. Long-term morphologic effects of antiglaucoma drugs on the conjunctiva and Tenon's capsule in glaucomatous patients. Ophthalmology. 1989; 96:327-335.

69. Pisella PJ, Pouliquen P, Baudouin C. Prevalence of ocular symptoms and signs with preserved and preservative free glaucoma medication. Br J Ophthalmol. 2002;86:418-423.

70. Fechtner RD, Godfrey DG, Budenz D, Stewart JA, Stewart WC, Jasek MC. Prevalence of ocular surface complaints in patients with glaucoma using topical intraocular pressure-lowering medications. Cornea. 2010;29:618-621. 
71. Davies NM, Farr SJ, Hadgraft J, Kellaway IW. Evaluation of mucoadhesive polymers in ocular drug delivery, I: viscous solutions. Pharm Res. 1991;8:1039-1043.

72. Mundada AS, Avari JG. In situ gelling polymers in ocular drug delivery systems: a review. Crit Rev Ther Drug Carrier Syst. 2009;26:85-118.

73. Kimura H, Ogura Y. Biodegradable polymers for ocular drug delivery. Opbthalmologica. 2001;215:143-155.

74. Davies NM, Farr SJ, Hadgraft J, Kellaway IW. Evaluation of mucoadhesive polymers in ocular drug delivery, II: polymer-coated vesicles. Pharm Res. 1992;9:1137-1144.
75. Herrero-Vanrell R, Fernandez-Carballido A, Frutos G, Cadorniga R. Enhancement of the mydriatic response to tropicamide by bioadhesive polymers. J Ocul Pharmacol Ther. 2000;16:419428.

76. Benedetto DA, Shah DO, Kaufman HE. The instilled fluid dynamics and surface chemistry of polymers in the preocular tear film. Invest Ophthalmol. 1975;14:887-902.

77. Johnston TP, Dias CS, Mitra AK. Mucoadhesive polymers in ophthalmic drug delivery. Opbthalmic Drug Deliv Syst. 2003;13:409435 . 